\title{
Functional miRNAs in breast cancer drug resistance
}

This article was published in the following Dove Press journal:

OncoTargets and Therapy

\author{
Weizi Hu${ }^{1-3, *}$ \\ Chunli $\operatorname{Tan}^{1-3, *}$ \\ Yunjie $\mathrm{He}^{4}$ \\ Guangqin Zhang ${ }^{2}$ \\ Yong $\mathrm{Xu}^{3,5}$ \\ Jinhai Tang'
}

'Department of General Surgery, The First Affiliated Hospital of Nanjing Medical University, ${ }^{2}$ School of Basic Medicine and Clinical Pharmacy, China Pharmaceutical University, ${ }^{3} \mathrm{Nanjing}$ Medical University Affiliated Cancer Hospital, ${ }^{4}$ The First Clinical School of Nanjing Medical University, ${ }^{5}$ Jiangsu Key Lab of Cancer Biomarkers, Prevention and Treatment, Nanjing Medical University, Nanjing, People's Republic of China

*These authors contributed equally to this work
Correspondence: Jinhai Tang Department of General Surgery, The First Affiliated Hospital of Nanjing Medical University, 300 Guangzhou Road, Nanjing 210029, People's

Republic of China

Email tangjh@njmu.edu.cn

Yong $\mathrm{Xu}$

Nanjing Medical University Affiliated Cancer Hospital, 42 Baiziting, Nanjing 210009, People's Republic of China Email yxu4696@njmu.edu.cn

\begin{abstract}
Owing to improved early surveillance and advanced therapy strategies, the current death rate due to breast cancer has decreased; nevertheless, drug resistance and relapse remain obstacles on the path to successful systematic treatment. Multiple mechanisms responsible for drug resistance have been elucidated, and miRNAs seem to play a major part in almost every aspect of cancer progression, including tumorigenesis, metastasis, and drug resistance. In recent years, exosomes have emerged as novel modes of intercellular signaling vehicles, initiating cell-cell communication through their fusion with target cell membranes, delivering functional molecules including miRNAs and proteins. This review particularly focuses on enumerating functional miRNAs involved in breast cancer drug resistance as well as their targets and related mechanisms. Subsequently, we discuss the prospects and challenges of miRNA function in drug resistance and highlight valuable approaches for the investigation of the role of exosomal miRNAs in breast cancer progression and drug resistance.
\end{abstract}

Keywords: microRNA, exosome, breast cancer, drug resistance

\section{Introduction}

Breast cancer $(\mathrm{BCa})$ is the most common invasive malignancy and the second leading cause of tumor-related death among women worldwide. ${ }^{1}$ Due to the improved early diagnosis and advanced therapeutic strategies, the mortality of $\mathrm{BCa}$ has been appreciably decreased. ${ }^{2}$ However, although the majority of patients were responsive to the initial treatment for certain time, the patients eventually developed more aggressive tumor forms that were generally resistant to the chemotherapy and radiotherapy. ${ }^{3,4}$ Thus, as a major challenge, metastasized recurrence leading to a poor prognosis remains to be conquered in $\mathrm{BCa}$ therapeutics. Current therapeutic strategies for treating $\mathrm{BCa}$ usually combine surgery with multiple adjuvant therapies, such as chemotherapy, radiotherapy, hormonal therapy, targeted therapy, or combination thereof. ${ }^{5}$ However, multiple drug resistance (MDR) is a major obstacle for successful systemic therapeutics. Multiple mechanisms involved in drug resistance have been elucidated in $\mathrm{BCa}$ treatment, including somatic mutations or epigenetic modifications within drug targets, deregulated apoptosis or survival, adapted signaling pathways or metabolic reprogramming, as well as drug reaching to the targets or drug transport modification within the tumor microenvironment. ${ }^{6-9}$ In this context, abnormal expression of miRNA leading to deregulation of gene expression has been implicated in the therapeutic resistance. ${ }^{9}$

miRNAs, a group of 20-25 nucleotides noncoding RNA that specifically bind to the 3 '-untranslated region of mRNA of the target genes, negatively regulate gene expression at post-transcriptional level. ${ }^{10}$ It has been well recognized that miRNA-mediated downregulation of gene expression is involved in tumorigenesis, metastasis, and tumor response to treatment. Particularly, increasing evidences have demonstrated that the 
dysfunction of miRNA contributes to therapeutic resistance in BCa. As shown in Tables 1-4, a number of miRNAs are deregulated in $\mathrm{BCa}$, which is associated with radioresistance and MDR including chemotherapy, endocrine therapy, and targeted therapy. ${ }^{9}$ However, individual miRNA can repress several hundred target genes, and single target gene is often regulated by multiple miRNAs. Importantly, exosomes function as vehicles delivering miRNAs from donating cells to accepting cells in the tumor microenvironment, which plays a pivotal role in the regulation of miRNA functions. ${ }^{11}$

Exosomes, extracellular vesicles secreted from various types of cells, carrying small molecules including miRNAs and proteins. ${ }^{12}$ Initially exosome was identified as cell debris containing metabolic products. However, the recent studies have verified that exosome is critical for cell-cell communication. ${ }^{13}$ As key components in the tumor microenvironment, exosomes shuttle bioactive molecules and lead to the exchange of genetic information and metabolic reprogramming of the recipient cells. ${ }^{14}$ Thus, exosome is thought to be critical for signal transduction between cells, and the function of exosome directly contributes to the promotion of proliferation, invasiveness, and metastasis of recipient cells, as well as transferring drug resistance, thereby enhancing tumor recurrence and metastasis. ${ }^{15}$ Our previous studies showed that tumor-derived exosomes transfer doxorubicin resistance to the susceptible $\mathrm{BCa}$ cells through exosomes shuttling miR-222. ${ }^{16}$

In this review, we focus on specific miRNAs associated with BCa drug resistance. Since substantial evidences predict that exosome-mediated dynamic and reciprocal cross-talks are essential for sustaining specific tumor microenvironment, we particularly highlight the recent novel findings that revealed the aspects of exosomal miRNAs implicated in drug resistance, which may be beneficial for seeking

Table I miRNAs involved in the regulation of chemotherapeutic resistance in breast cancer

\begin{tabular}{|c|c|c|c|c|c|}
\hline miRNA & Drug & Target(s) & $\begin{array}{l}\text { Expression } \\
\text { level* }\end{array}$ & Mechanism & Reference \\
\hline miR-505 & Doxorubicin & Akt3 (indirect) & $\downarrow$ & Not investigated & 19 \\
\hline miR-I8Ia & Doxorubicin & $\mathrm{Bcl}-2$ & $\downarrow$ & Increase apoptosis & 24 \\
\hline miR-663 & Doxorubicin & HSPG2 & $\uparrow$ & Inhibit apoptosis & 7 \\
\hline $\operatorname{miR}-25$ & Doxorubicin & ULKI & $\uparrow$ & Inhibit autophagy & 6 \\
\hline miR-145 & Doxorubicin & MRPI & $\downarrow$ & Induce intracellular doxorubicin accumulation & 8 \\
\hline miR-644a & Doxorubicin & CTBPI & $\downarrow$ & Inhibit EMT & 95 \\
\hline miR-I 28 & Doxorubicin & Bmi-I, ABCC5 & $\downarrow$ & Increase apoptosis & 23 \\
\hline miR-30c & $\begin{array}{l}\text { Doxorubicin } \\
\text { Paclitaxel }\end{array}$ & $\begin{array}{l}\text { TWFI (PTK9) } \\
\text { VIM, IL-I I }\end{array}$ & $\downarrow$ & Reverse EMT & 32 \\
\hline miR-326 & Doxorubicin & MDR-I & $\downarrow$ & Downregulate MRP-I & 36 \\
\hline miR-I8Ia & Doxorubicin & $\mathrm{Bax}$ & $\uparrow$ & Inhibit apoptosis & 86 \\
\hline $\begin{array}{l}\text { miR-106b 25 } \\
\text { cluster }\end{array}$ & Doxorubicin & EP300 & $\uparrow$ & Activate EMT & 25 \\
\hline miR-34a & $\begin{array}{l}\text { Doxorubicin } \\
\text { Cisplatin }\end{array}$ & $\begin{array}{l}\text { HDACI } \\
\text { HDAC7 }\end{array}$ & $\uparrow$ & Inhibit autophagic cell death & 30 \\
\hline $\begin{array}{l}\text { miR-345 } \\
\text { miR-7 }\end{array}$ & Cisplatin & MRPI & $\downarrow$ & Uncharacterized & 27 \\
\hline miR-302b & Cisplatin & $\begin{array}{l}\text { E2FI (direct) } \\
\text { ATM (indirect) }\end{array}$ & $\downarrow$ & Inhibit cell cycle progression & 28 \\
\hline miR-24 & Cisplatin & BimL, FIHI & $\uparrow$ & Promote EMT and CSCs & 79 \\
\hline miR-129-3p & Docetaxel & CPIO0 & $\uparrow$ & Reduce cell cycle arrest and apoptosis & 33 \\
\hline $\operatorname{miR}-34 a$ & Docetaxel & BCL-2, CCNDI & $\uparrow$ & Inhibit apoptosis & 87 \\
\hline miR-I25b & Paclitaxel & Sema4C & $\downarrow$ & Reverse EMT & 35 \\
\hline miR-I00 & Paclitaxel & $\mathrm{mTOR}$ & $\downarrow$ & Enhance cell cycle arrest and apoptosis & 31 \\
\hline miR-I25b & Taxol & Bakl & $\uparrow$ & Inhibit apoptosis & 34 \\
\hline $\operatorname{miR}-484$ & Gemcitabine & CDA & $\downarrow$ & $\begin{array}{l}\text { Promote proliferation and cell-cycle } \\
\text { redistribution }\end{array}$ & 37 \\
\hline miR-200 & Carboplatin & Zeb & $\downarrow$ & Reverse EMT & 99 \\
\hline $\operatorname{miR}-218$ & MDR & Survivin & $\downarrow$ & Enhance apoptosis & 38 \\
\hline miR-205 & $\begin{array}{l}\text { Doc, Dox } \\
\text { plus CTX }\end{array}$ & VEGFA, FGF2 & $\downarrow$ & Inhibit PI3K/Akt/mTOR pathway and CSCs & 37 \\
\hline
\end{tabular}

Note: *Upregulation $(\uparrow)$ or downregulation $(\downarrow)$ of miRNAs in drug-resistant cell lines/tissues.

Abbreviations: EMT, epithelial-mesenchymal transition; CSC, cancer stem cell. 
Table 2 miRNAs involved in the regulation of endocrine resistance in breast cancer

\begin{tabular}{|c|c|c|c|c|c|}
\hline miRNA & Drug & Target(s) & $\begin{array}{l}\text { Expression } \\
\text { level* }\end{array}$ & Mechanism & Reference \\
\hline miR-45I & Tamoxifen & $14-3-3 \zeta$ & $\downarrow$ & $\begin{array}{l}\text { Inhibit PI3K/Akt/mTOR pathway and } \\
\text { enhance apoptosis }\end{array}$ & 77 \\
\hline $\mathrm{miR}-45 \mathrm{Ia}$ & Tamoxifen & $14-3-3 \zeta, E R \alpha$ & $\downarrow$ & Inhibit autophagy & 47 \\
\hline miR-320a & Tamoxifen & $\begin{array}{l}\text { ARPP-19, ERRc, } \\
\text { c-Myc, Cyclin }\end{array}$ & $\downarrow$ & $\begin{array}{l}\text { Activation of the c-Myc and Cyclin DI } \\
\text { pathways }\end{array}$ & 46 \\
\hline $\begin{array}{l}\text { miR-15a } \\
\text { miR-16 }\end{array}$ & Tamoxifen & Cyclin EI, Bcl-2 & $\downarrow$ & Promote cell growth arrest and apoptosis & 44,91 \\
\hline miR-378a-3p & Tamoxifen & GOLTIA & $\downarrow$ & Uncharacterized & 51 \\
\hline $\operatorname{miR}-342$ & Tamoxifen & Uncharacterized & $\downarrow$ & Promote apoptosis and cell cycle progression & 49 \\
\hline miR-574-3p & Tamoxifen & CLTC & $\downarrow$ & Not investigated & 52 \\
\hline miR-873 & Tamoxifen & CDK3 & $\downarrow$ & $\begin{array}{l}\text { Inhibit ER } \alpha \text { activity; restore anti- } \\
\text { proliferative effect }\end{array}$ & 43 \\
\hline miR-375 & Tamoxifen & MTDH & $\downarrow$ & Reverse EMT & 50 \\
\hline $\operatorname{miR}-2 \mid 4$ & $\begin{array}{l}\text { Tamoxifen } \\
\text { Fulvestrant }\end{array}$ & UCP2 & $\downarrow$ & $\begin{array}{l}\text { Inhibit inhibiting } \mathrm{PI} 3 \mathrm{~K} / \mathrm{Akt} / \mathrm{mTOR} \\
\text { pathway and enhance apoptosis }\end{array}$ & 48 \\
\hline $\operatorname{miR}-519 a$ & Tamoxifen & PTEN, RBI, CDKNIA & $\uparrow$ & Promote proliferation, inhibit apoptosis & 17 \\
\hline miR-I0I & Tamoxifen & MAGI-2 & $\uparrow$ & Promote PI3K pathway & 53 \\
\hline miR-30I & Tamoxifen & $\begin{array}{l}\text { FOXF3, BBC3, } \\
\text { PTEN, COL2AI }\end{array}$ & $\uparrow$ & Uncharacterized & 56 \\
\hline $\operatorname{miR}-22 \mathrm{I} / 222$ & Fulvestrant & $\beta$-Catenin, TGF- $\beta$ & $\uparrow$ & $\begin{array}{l}\text { Deregulate multiple signaling pathways } \\
\text { including } \beta \text {-catenin and TGF- } \beta\end{array}$ & 78 \\
\hline $\operatorname{miR}-22 \mathrm{I} / 222$ & 4-hydroxytamoxifen & P27kip I & $\uparrow$ & Promote cell cycle arrest & 42 \\
\hline
\end{tabular}

Note: *Upregulation $(\uparrow)$ or downregulation $(\downarrow)$ of miRNAs in drug-resistant cell lines/tissues.

Abbreviations: EMT, epithelial-mesenchymal transition; CSC, cancer stem cell; TGF- $\beta$ transforming growth factor- $\beta$.

more effective therapeutic targets for the improvement of $\mathrm{BCa}$ treatment.

\section{miRNAs involved in $\mathrm{BCa}$ drug resistance}

The function of miRNA influences a variety of physiological and pathological processes by regulation of the target genes expression, which is generally implicated in tumor progression and resistance to treatment. A number of miRNAs were identified to be involved in $\mathrm{BCa}$ drug resistance by screening the established resistant cell or tissue models using either high-throughput sequencing or miRNA microarray. ${ }^{17}$ Subsequently, functional validation was conducted to assess the role of miRNA in drug resistance by ascertaining the expression of target genes and the alteration of related pathways. Finally, the selected candidate miRNAs were evaluated by using animal experimental models and/or clinical samples, which provided promising approaches to discover the

Table 3 miRNAs involved in regulation of target therapy resistance in breast cancer

\begin{tabular}{|c|c|c|c|c|c|}
\hline miRNA & Drug & Target(s) & $\begin{array}{l}\text { Expression } \\
\text { level* }\end{array}$ & Mechanism & Reference \\
\hline \multirow[t]{2}{*}{ miR-2I } & Trastuzumab & PTEN & $\uparrow$ & Promote PI3K/Akt pathway & $71-73$ \\
\hline & & PDCD4 & & and IL6/STAT3/NFKB pathway & \\
\hline miR-22I & Trastuzumab & PTEN & $\uparrow$ & Promote PI3K/Akt pathway & 75 \\
\hline miR-2I0 & Trastuzumab & Uncharacterized & $\uparrow$ & Uncharacterized & 76 \\
\hline miR-205-5p & Trastuzumab & P63 & $\uparrow$ & Promote EGFR pathway & 78 \\
\hline miR-200c & Trastuzumab & ZNFI 7 and ZEBI & $\downarrow$ & Inhibit TGF- $\beta$ signaling & 79 \\
\hline miR-542-3p & Trastuzumab & AKT & $\downarrow$ & Inhibit PI3K pathway & 80 \\
\hline miR-375 & Trastuzumab & IGFIR, AKT & $\downarrow$ & Inhibit PI3K/Akt pathway & 81 \\
\hline miR-630 & Lapatinib & IGFIR & $\downarrow$ & Uncharacterized & 82 \\
\hline \multirow[t]{2}{*}{ miR-16 } & Trastuzumab & Cyclin and FUBPI & $\downarrow$ & Enhance chromatin & 83 \\
\hline & Lapatinib & & & accessibility & \\
\hline miR-7 & Trastuzumab & EGFR & $\downarrow$ & Suppress EGFR expression & 84 \\
\hline miR-5I5 & Trastuzumab & CD44 & $\downarrow$ & Inhibit CSC marker & 103 \\
\hline
\end{tabular}

Note: *Upregulation $(\uparrow)$ or downregulation $(\downarrow)$ of miRNAs in drug-resistant cell lines/tissues.

Abbreviations: EGFR, epithelial growth factor receptor; CSC, cancer stem cell; TGF- $\beta$, transforming growth factor- $\beta$. 
Table 4 Exosomal miRNA involved in cancer resistance

\begin{tabular}{|c|c|c|c|c|c|c|c|}
\hline $\begin{array}{l}\text { Exosomal } \\
\text { miRNA }\end{array}$ & Drug & $\begin{array}{l}\text { Expression } \\
\text { level* }\end{array}$ & $\begin{array}{l}\text { Cancer } \\
\text { type }\end{array}$ & $\begin{array}{l}\text { Donor } \\
\text { cell }\end{array}$ & $\begin{array}{l}\text { Recipient } \\
\text { cell }\end{array}$ & Target(s)/mechanism & Reference \\
\hline miR-222 & Doxorubicin & $\uparrow$ & $\mathrm{BCa}$ & MCF-7/R & MCF-7/S & Uncharacterized & 16 \\
\hline $\mathrm{miR}-22 \mathrm{I} / 222$ & Tamoxifen & $\uparrow$ & $\mathrm{BCa}$ & MCF-7/R & MCF-7/S & P27, ER $\alpha /$ unknown & 136 \\
\hline miR-I55 & Multidrug & $\uparrow$ & NBL & NBL & Monocyte & TERFI - increase telomerase activity & 138 \\
\hline miR-I55 & Gemcitabine & $\uparrow$ & PDA & Pancl/R & Pancl/S & TP53INPI/enhance apoptosis & 139 \\
\hline $\mathrm{miR}-222-3 p$ & Gemcitabine & $\uparrow$ & NSCLC & A549/R & A549/R & SOCS3 - enhance Jak2/Stat3 and Bcl-2 & $|4|$ \\
\hline miR-9 & Temozolomide & $\uparrow$ & GBM & MSC & GBM & Efflux drug & 146 \\
\hline miR-2I & Paclitaxel & $\uparrow$ & OC & CAA/CAF & OC cell & APAFI/inhibit apoptosis & 13 \\
\hline miR-2I & Cisplatin & $\uparrow$ & GC & TAM & GC cell & PTEN/enhance PI3K/AKT & 144 \\
\hline miR-100-5p & Cisplatin & $\downarrow$ & NSCLC & A549/R & A549/S & mTOR & 142 \\
\hline miR-I34 & |7-AAG and PU-H7| & $\downarrow$ & $\mathrm{BCa}$ & MCF-7/R & MCF-7/S & STAT5B, Hsp90/unknown & 137 \\
\hline miR-I 22 & Multidrug & $\downarrow$ & $\mathrm{HCC}$ & AMSC & $\mathrm{HCC}$ & CCNGI, IGFIR, and ADAMI0/unknown & 145 \\
\hline miR-34a & Docetaxel & $\downarrow$ & PC & $\mathrm{PC} 3 / \mathrm{R}$ & $\mathrm{PC} 3 / \mathrm{S}$ & Bcl-2/promote apoptosis & 143 \\
\hline miR-146a-5p & Cisplatin & $\downarrow$ & NSCLC & A549/R & A549/R & Atg12/inhibit autophagy & 147 \\
\hline
\end{tabular}

Note: *Upregulation $(\uparrow)$ or downregulation $(\downarrow)$ of miRNAs in drug resistant cell lines/tissues.

Abbreviations: R, resistant; S, sensitive; BCa, breast cancer; PC, prostate cancer; OC, ovarian cancer; HCC, hepatocellular carcinoma; GC, gastric cancer; NBL, neuroblastoma; PDA, pancreatic ductal adenocarcinoma; NSCLC, non-small cell lung cancer; GBM, glioblastoma multiforme; TAM, tumor-associated macrophage; AMSC, adipose tissue-derived mesenchymal stem cell; MSC, mesenchymal stem cell.

potential drug targets for improving $\mathrm{BCa}$ therapeutics and prognosis. Clinically used drugs for treating BCa mainly involve in chemotherapy, hormone therapy, and targeted therapy. ${ }^{18}$ In this study, we summarize drug resistance and relevant miRNA-mediated mechanisms in $\mathrm{BCa}$.

\section{Chemotherapy resistance}

$\mathrm{BCa}$ patients with high risk of recurrence are generally recommended for adjuvant chemotherapy after definitive surgery. ${ }^{18}$ Doxorubicin (adriamycin) was the first-line anticancer drug to treat $\mathrm{BCa}$ which blocks DNA replication. Correspondingly, miR-505, miR-128, and miR-145 function as tumor suppressors, which are downregulated in doxorubicinresistant $\mathrm{BCa}$, and upregulation of these miRNAs led to reversal of doxorubicin resistance. ${ }^{8,19-23}$ In contrast, miR-663, miR-181a, and miR-106b 25 clusters serve as oncogenic miRNAs; downregulation of them resulted in enhancement of the sensitivity of doxorubicin-resistant cells. ${ }^{7,24,25}$

Similar to doxorubicin, cisplatin is used to treat multiple types of cancer by inhibiting DNA replication. ${ }^{26}$ A microarray screening for miRNA expression signatures in cisplatinresistant $\mathrm{BCa}$ cells versus sensitive $\mathrm{BCa}$ cells has shown upregulation of 46 miRNAs but downregulation of 57 miRNAs. ${ }^{27}$ In particular, miR-146a, miR-10a, miR-221/222, miR-345, miR-200b, and miR-200c were significantly deregulated in the resistant cells. ${ }^{27}$ Functional validation experiments indicated that miR-345 and miR-7 endow the cisplatin-resistant phenotype, while miR-302b can sensitize BCa cells to cisplatin. ${ }^{27,28}$
In addition, docetaxel and paclitaxel are often used to treat cancers by interfering the function of microtubules during cell division. ${ }^{29}$ It has been reported that miR-34a, miR-100, and miR-30c were downregulated in paclitaxel-resistant BCa cells. ${ }^{30-32}$ By contrast, miR-129-3p was upregulated in docetaxel-resistant $\mathrm{BCa}$ cells and contributed to docetaxel resistance. ${ }^{33}$ However, two studies present controversial results regarding the role of $\mathrm{miR}-125 \mathrm{~b}$ in the regulation of paclitaxel resistance in $\mathrm{BCa}$. Zhou et al primarily demonstrated that miR-125b was increased in paclitaxel-resistant $\mathrm{BCa}$ cells as an oncogenic miRNA. ${ }^{34}$ While Yang et al reported that miR-125b presumably serves as a tumor suppressor miRNA 35 (Table 1).

Moreover, it is recognized that miR-326 and miR-484 can reverse MDR phenotype; nevertheless, $\mathrm{miR}-218$ and miR-205 contribute to the acquisition of MDR in BCa cells. ${ }^{36-39}$

\section{Hormone therapy resistance}

Since $\sim 70 \%$ of BCa patients exhibit high levels of estrogen receptor- $\alpha$ (ER- $\alpha),{ }^{40}$ targeting ER- $\alpha$ seems to be the most valuable endocrine-based therapy. Several modulators of ER were selected to treat ER-positive BCa patients. ${ }^{41}$ In particular, tamoxifen, a well-documented hormone therapeutic drug, is able to bind to ER and block the interaction between estrogen and ER. ${ }^{42,43}$ Unfortunately, resistance and disease relapse have limited its long-term therapeutic efficacy. ${ }^{4}$ Manavalan et al initially screened miRNA expression profiles and identified multiple miRNAs deregulated in tamoxifenresistant (TamR) cells versus the sensitive control cells. ${ }^{42}$ 
The downregulation of miRNAs in TamR BCa cells was further confirmed to consist of miR-15a, miR-16, miR-320, miR-451, miR-214, miR-342, miR-873, miRNA-375, miR-378a-3p, and miR-574-3p. Subsequently, mechanistic studies have ascertained that these miRNAs play the roles of tumor suppressors due to the inhibition of multiple cell survival signaling pathways. ${ }^{43,45-52}$ Conversely, miR-101, miR-221/222, miR-301, and miRNAs-C19MC clusters were found to highly express in TamR BCa cells. ${ }^{17,53-56}$ (Table 2).

\section{Targeted therapy resistance}

Overexpression of human epidermal growth factor receptor 2 (HER2) is highly correlated to BCa metastasis and poor prognosis. ${ }^{57}$ HER2 targeted therapy has successfully achieved excellent results for treating HER2-positive BCa. ${ }^{58}$ Trastuzumab, a humanized monoclonal antibody targeting HER2, lapatinib, a small-molecule tyrosine kinase inhibitor dually targeting HER2 and epithelial growth factor receptor (EGFR), have largely improved therapy outcome and prognosis. ${ }^{59-65}$ However, despite their initial efficacy achieved for the early patient response, most of the patients eventually developed resistance after 1 year. ${ }^{66-70}$ Several mechanistic studies have revealed that deregulation of miRNA is involved in $\mathrm{BCa}$ trastuzumab resistance. Correlation of upregulation of miR-21 with trastuzumab resistance was validated in vitro and in vivo. ${ }^{71-73}$ However, one study asserted that the results from clinical research did not display the association between miR-21 expression and recurrent disease after adjuvant trastuzumab treatment. ${ }^{74}$

In addition to miR-21, miR-221 has been reported to promote trastuzumab resistance and metastasis of HER2-positive BCa. ${ }^{75}$ Also, circulating miR-210 levels in plasma from HER2-positive and trastuzumab-resistant $\mathrm{BCa}$ patients were determined to be correlated to $\mathrm{BCa}$ growth and metastases, suggesting that plasma miR-210 may serve as a predictive biomarker in surveillance of the therapeutic responsiveness. ${ }^{76}$ Furthermore, miR-205 was identified as a tumor suppressor, whose expression is downregulated in $\mathrm{BCa}$ cells, but is upregulated in patient-derived cancer stem cells (CSCs). ${ }^{77,78}$ miR-200c seemed to restore trastuzumab sensitivity and suppress invasion of BCa cells. ${ }^{79}$ Downregulation of miR-542-3p and miR-375 was also reported to contribute to trastuzumab resistance. ${ }^{80,81}$ In addition, miR-630 was found to be downregulated in lapatinib-resistant cell lines, ${ }^{82}$ while miR-16 expression was upregulated by trastuzumab and lapatinib. ${ }^{83}$ In the case of HER2 $\Delta 16$, an oncogenic isoform of HER2 has been reported to prompt metastasis and MDR including trastuzumab and tamoxifen. ${ }^{84}$ The results from miRNA array have indicated that $16 \mathrm{miRNAs}$ were abnormally expressed in HER2 $\Delta 16$-expressed cells, particularly miR-7 appeared to have a 4.8 -fold reduction. ${ }^{84}$

\section{Mechanisms involved in miRNA- mediated therapeutic resistance of BCa}

The function of miRNA in drug resistance has been ascribed to the alteration of drug transporters leading to efflux of anticancer agents, ${ }^{113,114,118}$ modification of autophagy/apoptosis to enhance survival, ${ }^{24,28,47,48,85,86}$ promotion of growth factors to disturb asso-

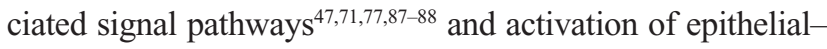
mesenchymal transition (EMT) process and augment of CSC populations to promote metastasis ${ }^{25,32,50,79,80}$ (Figure 1).

\section{Autophagy/apoptosis}

Autophagy is a lysosome-mediated intracellular self-catabolic degradation process for maintaining cellular homeostasis. ${ }^{91}$ Recent studies suggest that miRNA affects drug resistance by the regulation of autophagy that is considered to be a surviving mechanism..$^{92,93}$ miR-451a is involved in $\mathrm{BCa}$ resistance to tamoxifen through significantly reduced autophagosomes. ${ }^{47} \mathrm{~A}$ novel compound isoliquiritigenin can reverse chemoresistance of $\mathrm{BCa}$ cells by negatively regulating miR-25, and overexpression of miR-25 was validated to stop isoliquiritigenin-induced autophagy and trigger chemosensitization by targeting ULK $1 .^{6}$

Nevertheless, as the procedure of programmed cell death, apoptosis is considered to be involved in sensitization of cancers to treatment, which is regulated by pro-apoptotic regulators like caspases and/or antiapoptotic regulators including Bcl-2 family. ${ }^{94,95}$ As a tumor suppressor, miR-505 induces cell apoptosis via targeting Akt3 that participates in metastasis and drug resistance. ${ }^{19-22}$ miR-100 sensitizes BCa cells to paclitaxel by inducing cell apoptosis mainly by targeting mTOR. ${ }^{31}$ Bak1 was validated to be a direct target of miR-125b, which enhanced docetaxel-induced apoptosis. ${ }^{34}$ In addition, NF- $\mathrm{KB}$-dependent STAT3 activation contributes to the upregulation of miR-181a to suppress BAX, resulting in decreased apoptosis and increased invasion of triple-negative breast cancer (TNBC).${ }^{95}$ Inhibition of miR-181a significantly enhanced the sensitivity of TNBC to doxorubicin. ${ }^{96}$ Upregulation of miR-34a converted docetaxel resistance of $\mathrm{BCa}$ cells by downregulation of $\mathrm{Bcl}-2 .{ }^{97}$ In addition to miR-34a, miR-15a, miR-16, and miR-214 were also found to target Bcl-2 family in TamR cells. ${ }^{45,48,49}$ Moreover, miR-218 was found to contribute to the development of MDR in BCa cells by targeting survivin. ${ }^{38}$ 


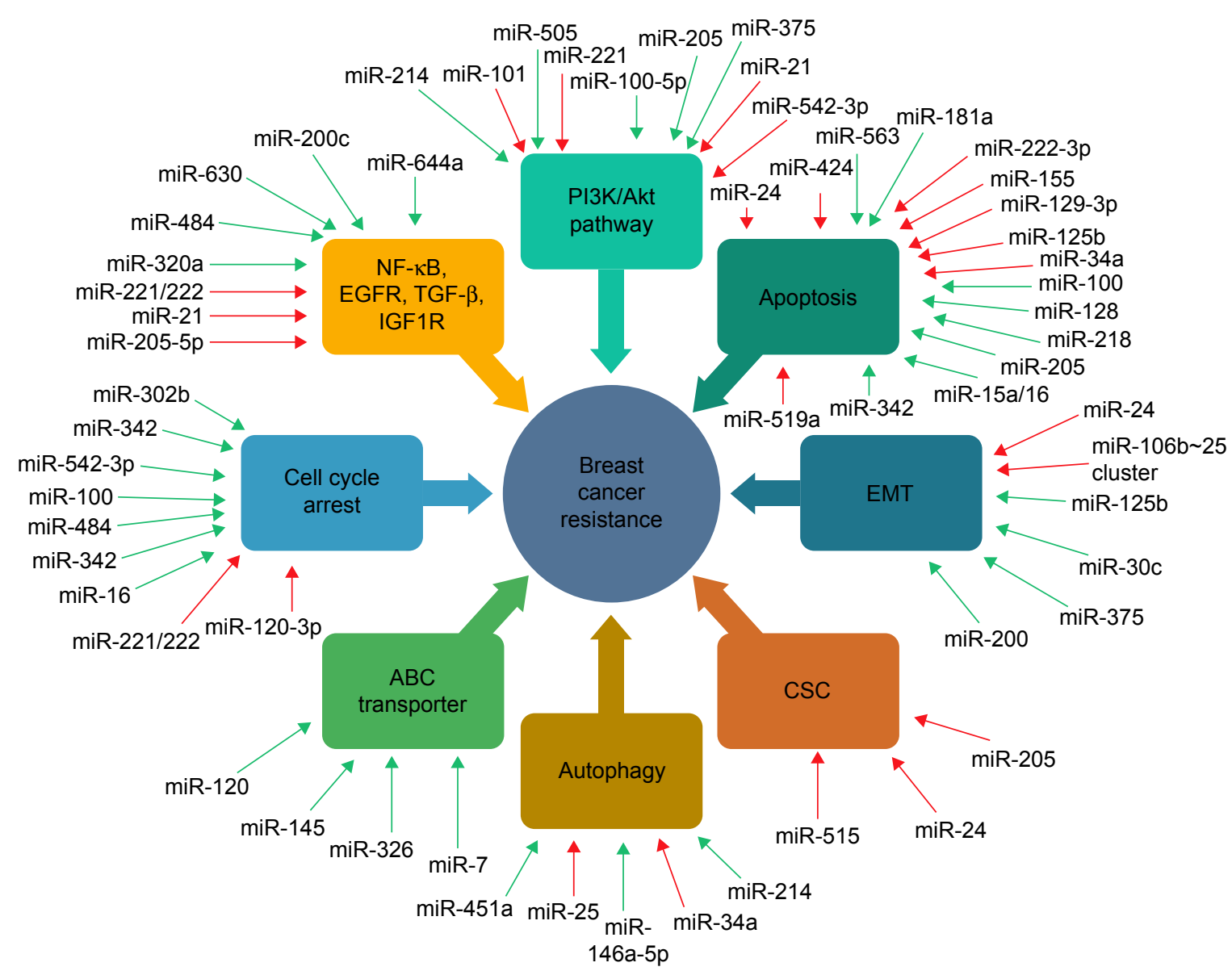

Figure I miRNA-mediated mechanisms involved in the regulation of BCa drug resistance. Red arrows indicate oncogenic miRNAs and green arrows represent cancer suppressor miRNAs.

Abbreviations: BCa, breast cancer; EGFR, epithelial growth factor receptor; CSC, cancer stem cell; TGF- $\beta$, transforming growth factor- $\beta$; EMT, epithelial-mesenchymal transition.

\section{Cell cycle arrest}

It has been shown that there is a balance between cell cycle arrest and cell death in cancer therapy. ${ }^{98} \mathrm{CDKs}$ act as dominators in mammalian for the regulation of cell cycle through phosphorylation of their selected cyclins by maintaining exit or entry to the different phases of the cell cycle. ${ }^{99,100}$ Several miRNAs participate in cell cycle regulation by targeting CDKs, cyclins, and E2F. Overexpression of miR-302b can sensitize BCa cells to cisplatin by targeting E2F1, a major regulator of the G1/S transition. ${ }^{28}$ In TamR $\mathrm{BCa}$ cells, miR-221/222 has been shown to target cell cycle inhibitor p27Kip1 that contributes to antagonizing cell death and promoting hormone-independent cell growth. ${ }^{42}$ Restoration of miR-320a expression is able to sensitize TamR cells to tamoxifen through the downregulation of c-Myc and Cyclin D1 ${ }^{46}$ In addition, the forced expression of miR-16 reduced $\mathrm{BCa}$ resistance to trastuzumab and lapatinib, and the underlying mechanism involves inhibition of c-Myc-enhanced chromatin assessibility. ${ }^{83}$
In contrast, several miRNAs were identified as tumor suppressors, miR-15a/16 inhibits Cyclin E1 and promotes tamoxifen-induced cell cycle arrest. ${ }^{101}$ Elevating miR-873 in TamR cells restored tamoxifen sensitivity by targeting CDK $3{ }^{43}$ In addition to directly targeting BCL-2, miR-34a also negatively regulates Cyclin-D1-regulated G1 arrest in response to docetaxel-induced apoptosis. ${ }^{97}$ Furthermore, miR-342 seems to regulate the expression of genes involved in tamoxifen-induced cell cycle arrest, but the specific targets for miR-342 remain uncharacterized. ${ }^{49}$

\section{CSCs and EMT}

The intractable tumor relapses suggest that not all cells have been targeted, for example, CSCs may be a typical "escaping cells" that are capable of regenerating the tumor and do not respond to therapy drugs. ${ }^{77} \mathrm{CSCs}$ are thought to be major contributors for drug resistance by activating HIF $1 \alpha$ under hypoxic condition. ${ }^{89}$ It has been reported that miR-24 increases the expression of CSC markers, conferring cisplatin 
resistance. ${ }^{89}$ Although miR-205 was identified as a tumor suppressor, it has appeared to be upregulated in patientderived CSCs. ${ }^{77,78}$ Similarly, miR-205 suppresses ErbB3 expression in $\mathrm{BCa}$ cells, whereas it inhibits EFGR by targeting p63 in BCa CSCs. ${ }^{78,102}$ In addition, CD44 is a putative marker of CSCs, highly expressed in trastuzumab-resistant HER2-positive BCa. Knockdown of CD44 can efficiently restore the trastuzumab sensitivity of the resistant cells. ${ }^{103}$ Several miRNAs have been shown to regulate CD44 expression in CSCs, particularly miR-515 is essential for the regulation of CD44 in response to trastuzumab resistance. ${ }^{103}$

Increasing evidences suggest that the function of miRNA is particularly involved in the EMT process that plays a crucial role in MDR by the promotion of tumor metastasis. ${ }^{104} \mathrm{E}$-cadherin transcriptional activator EP300 is suppressed by miR106b 25 cluster, leading to acquired doxorubicin resistance by activating EMT. ${ }^{25}$ In addition, miR-24 confers cisplatin resistance by enhancing EMT process by targeting BimL and $\mathrm{F} 1 \mathrm{H} 1{ }^{89}$ In contrast, miR-644a suppresses a transcription repressor CTBP1, resulting in enhanced p53-mediated inhibition of EMT. ${ }^{105}$ Furthermore, miR-30c increases chemoresistance by targeting EMT-related cytokines in $\mathrm{BCa}$, such as vimentin, stress fiber F-actin, twinfilin 1, Interleukin-6, and interleukin- $11 .{ }^{32}$ Loss of miRNA-375 in TamR cells resulted in the activation of EMT, and ectopic expression of miRNA375 in TamR cells was able to restore tamoxifen sensitivity by reversing EMT. ${ }^{50}$ Intriguingly, miR-125b serves as a tumor suppressor miRNA through the inhibition of EMT by targeting Sema4C, regardless of its effect on apoptosis. ${ }^{35}$

It is worth noting that cells undergoing EMT often obtain properties associated with CSCs. ${ }^{106}$ Thus, EMT can cause drug resistance by inducing CSCs. TNBC accounts for $\sim 15 \%-20 \%$ of all BCa cases, which is often documented as clinical chemoresistance due to the lack of molecular targets, particularly claudin-low tumors with extremely rich CSCs and EMT markers. ${ }^{90,107,108}$ As a central regulator of EMT, miR-200 has been shown to inhibit self-renewal capabilities of CSCs and keep cells in an epithelial state by suppressing the function of Zeb transcription factors. ${ }^{109-112}$ Induction of miR-200 in claudin-low tumors resulted in the suppression of tumor growth by inhibiting the functions of CSCs and reversal of EMT..$^{90}$

\section{Growth factor-related pathways}

Numerous studies have revealed multiple signaling pathways involved in therapeutic resistance of $\mathrm{BCa}$ and suggested many important molecular targets for the development of new drugs to treat aggressive $\mathrm{BCa}$ that are resistant to transitional chemotherapy and radiotherapy. In particular, growth factors, cytokines including chemokines, serve as major contributors for promoting BCa metastasis and leading to therapeutic resistance.

\section{$\mathrm{PI} 3 \mathrm{~K} / \mathrm{Akt} / \mathrm{mTOR}$}

$\mathrm{PI} 3 \mathrm{~K} / \mathrm{Akt} / \mathrm{mTOR}$-mediated amplification of growth factors is well recognized to play a pivotal role in $\mathrm{BCa}$ metastasis and drug resistance. ${ }^{47,48,113}$ Multiple miRNAs were identified to participate in $\mathrm{BCa}$ MDR through the regulation of $\mathrm{PI} 3 \mathrm{~K} /$ Akt/mTOR signaling pathway. For example, miR-205 and miR-214 enhance chemoresistance and TamR by inhibiting PI3K/Akt/mTOR pathway. ${ }^{39,48}$ However, phosphorylation of Akt and mTOR are reduced by miR-451, resulting in restored sensitivity to tamoxifen. ${ }^{47}$ Downregulation of miR-542-3p contributes to trastuzumab resistance in BCa partially through inhibiting PI3K.$^{80}$ In addition, PTEN, an inhibitor of PI3K, is a key regulator for PI3K/Akt/mTOR pathway. Reduction or loss of PTEN has been involved in $\mathrm{BCa}$ progression and drug resistance. ${ }^{66,72}$ PTEN was verified to be a target gene of miR-21 and miR-221..$^{73,75}$ In addition, miR-101 and miRNA-519a confer TamR and chemoresistance by targeting PTEN. ${ }^{17,53}$ Reducing miR-301 expression was validated to increase sensitivity to tamoxifen. ${ }^{56}$

\section{NF- $\kappa B$}

$\mathrm{NF}-\kappa \mathrm{B}$, stress responsible transcription factor, plays a crucial role in cancer progression and therapeutic resistance. ${ }^{114-117}$ In addition to IKK family identified as standard upstream signaling to activate NF- $\kappa \mathrm{B}, \mathrm{PI} 3 \mathrm{~K}$ and STAT3 can also trigger NF- $\kappa$ B activation. ${ }^{118}$ Through NF- $\kappa B$ transcriptional activation, miR-21 is uniquely highly expressed in HER2-positive $\mathrm{BCa}$ and is responsible for the resistance to trastuzumab. ${ }^{73}$ In addition to PTEN, PDCD4 was found as another direct target of miR-21. ${ }^{73}$ In contrast, miR-31 represses NF- $\mathrm{KB}$ activation and increases apoptosis in TNBC cells by targeting protein kinase $\mathrm{C}$ epsilon. ${ }^{119}$

\section{EGFR}

Overexpression of EGFR family containing ErbB1, HER1, HER2, HER3, and HER4 imperatively increases drug resistance of BCa. ${ }^{120-124}$ Notably, the activation of EGFR finally triggers $\mathrm{PI} 3 \mathrm{~K} / \mathrm{Akt} / \mathrm{mTOR}$ and STAT3 signaling pathways, resulting in increased cell survival by activating antiapoptotic proteins. ${ }^{120,125}$ miR-451 was reported to specifically target 14-3-3 $\zeta$, leading to enhanced apoptosis and sensitized $\mathrm{BCa}$ cells to endocrine drugs via inactivation of EGFR ${ }^{87} \mathrm{miR}-7$ was identified to suppress EGFR expression and sensitize 
HER $2 \Delta 16$ to the targeted therapy. ${ }^{84}$ In addition, miR-205 was also found as a tumor suppressor, sensitizing targeted therapy by suppressing HER3 and Zeb. ${ }^{78}$ However, it is upregulated in $\mathrm{BCa}$ CSCs and increases the therapeutic resistance through the regulation of P63-mediated EGFR activation. ${ }^{78,102}$

\section{Cytokines}

Cytokines including chemokines are important inflammatory factors and highly related to $\mathrm{BCa}$ progression and drug resistance. Several miRNAs have been involved in cytokine-mediated drug resistance of BCa due to the activation of EMT. Overexpression of miR-221/222 contributes to drug resistance through deregulation of multiple signaling pathways including $\beta$-catenin and transforming growth factor- $\beta$ (TGF- $\beta$ ). ${ }^{88,126}$ In addition, miR-200c suppresses TGF- $\beta$ signaling and counteracts trastuzumab resistance of BCa by targeting ZNF217 and ZEB1. ${ }^{79}$ Both miR-630 and miR-375 have been found to enhance patient responses to HER-targeting drugs by targeting IGF1R. ${ }^{81,82}$ Furthermore, miR-30c inhibits chemoresistance of $\mathrm{BCa}$ by targeting TWF1, an activator of EMT, leading to suppression of IL-6 and IL-11 production. ${ }^{32}$

\section{ATP binding cassette $(A B C)$ transporter} Overexpression of $\mathrm{ABC}$ transporters in cancer cells is considered to be a common mechanism of MDR due to efflux of drug substrates to maintain their concentrations below effective levels. ${ }^{127}$ Human ABC transporters are a large group of membrane protein complexes, including MDR1(P-gp) and MRP1 (ABCC1). ${ }^{127,128} \mathrm{ABCC} 5$, another member in $\mathrm{ABC}$ family, was targeted by miR-128, leading to sensitization of $\mathrm{BCa}$ to doxorubicin. ${ }^{23}$ In addition, miR-145 was able to inverse doxorubicin resistance in BCa by suppressing MRP1 and triggering drug efflux transporter. ${ }^{8}$ Targeting MRP1 by miR-326 was also validated to reverse MDR phenotype. ${ }^{36}$

\section{Commentary}

However, it is intriguing that there are some controversial results reported in response to the regulation of different sets of target genes. For example, downregulation of miR-181a was previously reported to inhibit $\mathrm{BCa}$ cell apoptosis induced by doxorubicin through the upregulation of $\mathrm{Bcl}-2,{ }^{24}$ while miR-181a was upregulated in TNBC cells in response to chemotherapy, which was activated by STAT3 to target BAX. ${ }^{96}$ Similarly, miR-125b was upregulated in paclitaxel-resistant BCa cells and target Bak1. ${ }^{34,129}$ Nevertheless, miR-125b was also shown to be downregulated in paclitaxel-resistant MCF-7 cells, leading to reverse EMT by targeting Sema 4C. ${ }^{35}$
Despite one miRNA targets different genes which may exert the same or opposite effects, the roles of miRNAs in drug resistance of $\mathrm{BCa}$ finally depend on their targets for achieved dominant effects in particular cellular and tissue types corresponding to the particular treatment. In addition, it also needs to be noted that multiple miRNAs may interact with one another or may interplay on gene expression through either cooperative effects or antagonist competition, which forms a complicated network to regulate all the target genes in cancers. However, to date, most of studies cited in this review described only the role of miRNA in drug resistance dependent upon the effect of single miRNA, but the concert action of multiple miRNAs contributes to the resistance remains obscure.

\section{Function of exosome in $\mathrm{BCa}$ chemoresistance}

Exosome is widely recognized to be an important transfer vehicle for cell-cell communication within the tumor microenvironment. Emerging evidences have demonstrated that exosome-mediated miRNA transfer between host-tumor cells plays a pivotal role in tumor progression and resistance to treatment. ${ }^{130}$

\section{Exosomal miRNA}

Expression profiles of miRNA in the established drug-resistant $\mathrm{BCa}$ cells have indicated that 22 miRNAs were concentrated in exosomes and correlated to resistance. ${ }^{131} \mathrm{We}$ and others have reported that exosome-derived miRNAs can transfer doxorubicin-resistant capacity from the resistant cells to their parent sensitive cells. ${ }^{132}$ Subsequently, we found that miR-222 in exosomes of doxorubicin-resistant cells was able to transfer into the sensitive cells and conferred resistance capacity to the recipient cells by inhibiting PTEN. To confirm the effect of exosome-derived miRNA transferring on drug resistance transmitting, we further enlarged the significance of the miRNA delivered by exosomes. The results suggested that the miRNA regulated drug resistance due to exosomes involving more infused microenvironment within transmitting resistant capacity through miRNA-mediated alteration of gene expression. ${ }^{16,132-135}$

In addition to doxorubicin, Wei et $\mathrm{al}^{136}$ have demonstrated distinct differences in the exosome concentration and size distribution between TamR cells and the sensitive cells. TamR cells seem to have an increased amount of exosomal RNA and proteins. Exosome secreted from TamR cells was able to enter into the sensitive cells and release miR-221/222, leading to TamR by targeting P27 and Era. ${ }^{136}$ Nevertheless, 
TNBC cells secrete miRNA-134-enriched exosomes and contribute to increased sensitivity to anti-Hsp90 drugs through the reduction of STAT5B and Hsp90, suggesting that TNBC-derived exosomes may have therapeutic potential as miRNAs delivery vesicles. ${ }^{137}$

In addition to $\mathrm{BCa}$, exosomal miRNAs involving drug resistance have been studied in other types of cancer. Exosomal miR-155 contributes to chemoresistance of neuroblastoma by targeting TERF1. ${ }^{138}$ Increase of exosomal miR-155 was also found to enhance gemcitabine resistance in pancreatic ductal adenocarcinoma cells through the enhancement of antiapoptotic activity. ${ }^{139}$ Exosomal miRNAs from lung cancer A549 cells were increased after exposure to cisplatin, which can endow the resistant capacity of the untreated cells. ${ }^{140}$ Exosomal miR-222-3p has been shown to enhance gemcitabine resistance by targeting SOCS3 in A549 cells. ${ }^{141}$ While exosomal miR-100-5p was decreased in cisplatin-resistant A549, leading to increase in cisplatin resistance through reverse regulation of mTOR. ${ }^{142}$ Exosomal miRNAs including miR-598, miR-34a, miR-146a, and miR-148a were significantly increased in docetaxel-resistant prostate cancer cells. ${ }^{143}$ Exosomal transfer of stromal-derived miR-21 can transmit paclitaxel resistance into ovarian cancer cells by targeting APAF $1 .{ }^{13}$ In addition, exosomes derived from tumor-associated macrophages can mediate cisplatin resistance by directly transferring miR-21 to target PTEN in gastric cancer cells. ${ }^{144}$ Interestingly, Lou et al successfully sensitized hepatocellular carcinoma to chemotherapy by using exosomes from adipose tissuederived mesenchymal stem cells for packaging miR-122. ${ }^{145}$ In addition, Munoz et al transferred exosomes carrying antimiR-9 into glioblastoma cells and achieved an enhanced therapeutic efficacy through the suppression of P-gp. ${ }^{146}$ Furthermore, the low levels of serum exosomal miR-146a-5p were found in advanced non-small cell lung cancer patients with higher recurrence rates, leading to sensitized cisplatin resistance by targeting Atg12 for inhibiting autophagy. ${ }^{147}$

\section{Other exosomal contents}

Except for miRNAs, other exosomal contents have been noted to participate in exosome-mediated drug resistance in $\mathrm{BCa}$. $\mathrm{P}$-gp exists in exosomes and contributes to drug resistance by pumping drugs out to maintain cellular levels beyond effective concentration. We have reported that exosome-mediated cell-cell transferring P-gp to be a main mechanism by which exosomes contribute to docetaxel resistance in BCa cells. ${ }^{127}$ Since TrpC5 can stimulate the formation of P-gp, TrpC5 was also accumulated in exosomes and promoted exosomes to trap P-gp for doxorubicin resistance in $\mathrm{BCa} .{ }^{148}$
Within the tumor microenvironment, cross-talk between stromal cells and cancer cells plays an important role in transfer of drug resistance through exosomal vehicles. It has been noted that exosomes transferred from stromal cells to $\mathrm{BCa}$ cells can activate antiviral pathway as well as increased interferon-related DNA damage resistance signature including STAT1, MX1, ISG15, OAS1, IFIT1, IFIT3, and IFI44, which has been validated to impact chemoresistance of BCa. ${ }^{149}$ In addition, Wang et al recently reported that bone marrow stromal cell-derived exosomes can transfer bortezomib resistance in multiple myeloma cells through the delivery of growth factors and cytokines. ${ }^{150}$

\section{Exosome in the tumor microenvironment}

Tumor microenvironment is often likened to the soil where tumor cells grow, which refers to the variety of normal cells, signaling molecules, blood vessels, and extracellular matrix surrounding the tumor cells. ${ }^{151}$ As a key component in the tumor microenvironment, exosomes shuttle bioactive molecules and mediate cellular communication in the tumor microenvironment, facilitating a more malignant and refractory tumor environment. The major function of exosome in the tumor microenvironment in response to drug resistance is considered to be a molecular shuttle. As described above, exosomes can enrich and transfer a variety of small molecules including miRNAs between donor cells and recipient cells. Recent studies suggest two main categories, namely from resistant cells to sensitive cells for transferring the resistant capacity as well as from stromal cells to their surrounded cancer cells for survival and resistance. ${ }^{13,132,136,140}$ The relevant stromal cells have been defined as cancer-associated fibroblasts, mesenchymal stem/stroma, and adipocytes.

Beyond its encapsulated abundant functional molecules, exosomes also participate in the regulation of drug resistance by acting as an efflux pump. The drugs and their metabolites can be encapsulated and exported by exosomes. ${ }^{152-154}$ Therefore, it is very promising to apply exosomes for targeted therapeutics for their unique advantages, because they have a good tolerance for their wide distribution in various human body fluids. Overall, exosomes can serve as an optimal carrier of drugs and functional molecules including diagnostic biomarkers and therapeutic targets, which may provide a promising approach for the improvement of anticancer therapy.

\section{Acknowledgments}

This review was partially supported by National Program on Key Precision Medicine Research Project of China 
(No 2016YFC0905900) to J Tang and Y Xu; Medical Training Program Foundation for the Talents by Jiangsu Provincial Department of Health (No 17 [2016]) to J Tang; and research grant from National Nature Science Foundation of China (No 81372199) to Y Xu.

\section{Disclosure}

The authors report no conflicts of interest in this work.

\section{References}

1. Smith RA, Cokkinides V, Brooks D, Saslow D, Brawley OW. Cancer screening in the United States. A review of current American Cancer Society guidelines and issues in cancer screening. CA Cancer J Clin. 2010;60(2):99-119.

2. DeSantis C, Ma J, Bryan L, Jemal A. Breast cancer statistics, 2013. CA Cancer J Clin. 2014;64(1):52-62.

3. O'Driscoll L, Clynes M. Biomarkers and multiple drug resistance in breast cancer. Curr Cancer Drug Targets. 2006;6(5):365-384.

4. Ellis LM, Hicklin D. Resistance to targeted therapies: refining anticancer therapy in the era of molecular oncology. Clin Cancer Res. 2009;15(24):7471-7478.

5. Kutanzi KR, Yurchenko OV, Beland FA, et al. MicroRNA-mediated drug resistance in breast cancer. Clin Epigenetics. 2011;2(2):171.

6. Wang Z, Wang N, Liu P, et al. MicroRNA-25 regulates chemoresistance-associated autophagy in breast cancer cells, a process modulated by the natural autophagy inducer isoliquiritigenin. Oncotarget. 2014; 5(16):7013-7026.

7. Haiyan H, Shuqin L, Xiuying C, et al. The overexpression of hypomethylated miR-663 induces chemotherapy resistance in human breast cancer cells by targeting heparin sulfate proteoglycan 2 (HSPG2). J Biol Chem. 2013;288(16):10973-10985.

8. Gao M, Miao L, Liu M, et al. miR-145 sensitizes breast cancer to doxorubicin by targeting multidrug resistance-associated protein-1. Oncotarget. 2016;7(37):59714-59726.

9. Mulrane L, Mcgee SF, Gallagher WM, et al. miRNA dysregulation in breast cancer. Cancer Res. 2013;73(22):6554-6562.

10. Penna E, Orso F, Taverna D. miR-214 as a key hub that controls cancer networks: small player, multiple functions. J Invest Dermatol. 2015; 135(4):960-969.

11. Milane L, Singh A, Mattheolabakis G, et al. Exosome mediated communication within the tumor microenvironment. J Control Release. 2015;219:278-294.

12. Sheridan C. Exosome cancer diagnostic reaches market. Nat Biotechnol. 2016;34(4):359-360.

13. Chi LAY, Co NN, Tsuruga T, et al. Exosomal transfer of stroma-derived miR21 confers paclitaxel resistance in ovarian cancer cells through targeting APAF1. Nat Commun. 2016;7:11150.

14. Zhang X, Yuan X, Shi H, et al. Exosomes in cancer: small particle, big player. J Hematol Oncol. 2015;8:83.

15. O'Driscoll L. Expanding on exosomes and ectosomes in cancer. $N$ Engl J Med. 2015;372(24):2359-2362.

16. Yu DD, Wu Y, Zhang XH, et al. Exosomes from adriamycin-resistant breast cancer cells transmit drug resistance partly by delivering miR-222. Tumour Biol. 2016;37(3):3227-3235.

17. Dweep H, Sticht C, Pandey P, et al. miRWalk - database: prediction of possible miRNA binding sites by "walking" the genes of three genomes. J Biomed Inform. 2011;44(5):839-847.

18. Sledge GW, Mamounas EP, Hortobagyi GN, et al. Past, present, and future challenges in breast cancer treatment. J Clin Oncol. 2014;32(19): 1979-1986.

19. Yamamoto Y, Yoshioka Y, Minoura K, et al. An integrative genomic analysis revealed the relevance of microRNA and gene expression for drug-resistance in human breast cancer cells. Mol Cancer. 2011; 10(1):135.
20. Vivanco I, Sawyers CL. The phosphatidylinositol 3-kinase AKT pathway in human cancer. Nat Rev Cancer. 2002;2(7):489-501.

21. Yuan XJ, Whang YE. PTEN sensitizes prostate cancer cells to death receptor-mediated and drug-induced apoptosis through a FADDdependent pathway. Oncogene. 2002;21(2):319-327.

22. Wan X, Yokoyama Y, Shinohara A, Takahashi Y, Tamaya T. PTEN augments staurosporine-induced apoptosis in PTEN-null Ishikawa cells by downregulating PI3K/Akt signaling pathway. Cell Death Differ. 2002;9(4):414-420.

23. Zhu Y, Yu F, Jiao Y, et al. Reduced miR-128 in breast tumor-initiating cells induces chemotherapeutic resistance via Bmi-1 and ABCC5. Clin Cancer Res. 2011;17(22):7105-7115.

24. Zhu Y, Wu J, Li S, et al. The function role of miR-181a in chemosensitivity to adriamycin by targeting Bcl-2 in low-invasive breast cancer cells. Cell Physiol Biochem. 2013;32(5):1225-1237.

25. Zhou Y, Hu Y, Yang M, et al. The miR-106b 25 cluster promotes bypass of doxorubicin-induced senescence and increase in motility and invasion by targeting the E-cadherin transcriptional activator EP300. Cell Death Differ. 2013;21(3):462-474.

26. Cheung HW, Jin DY, Ling MT, et al. Mitotic arrest deficient 2 expression induces chemosensitization to a DNA-damaging agent, cisplatin, in nasopharyngeal carcinoma cells. Cancer Res. 2005;65(4): $1450-1458$

27. Pogribny IP, Filkowski JN, Tryndyak VP, et al. Alterations of microRNAs and their targets are associated with acquired resistance of MCF-7 breast cancer cells to cisplatin. Int J Cancer. 2010;127(8): 1785-1794.

28. Cataldo A, Cheung DG, Balsari A, et al. miR-302b enhances breast cancer cell sensitivity to cisplatin by regulating E2F1 and the cellular DNA damage response. Oncotarget. 2016;7(1):786-797.

29. Sprowl JA, Parissenti A. Abstract 3550: Role of TNF $\alpha$ in the cytotoxicity of docetaxel and in docetaxel resistance in MCF-7 cells. Cancer Res. 2011;70(8 Suppl):3550.

30. Wu MY, Fu J, Xiao X, et al. MiR-34a regulates therapy resistance by targeting HDAC1 and HDAC7 in breast cancer. Cancer Lett. 2014; 354(2):311-319.

31. Zhang B, Zhao R, He Y, et al. Micro RNA 100 sensitizes luminal A breast cancer cells to paclitaxel treatment in part by targeting mTOR. Oncotarget. 2016;7(5):5702.

32. Bockhorn J, Dalton R, Nwachukwu C, et al. MicroRNA-30c inhibits human breast tumour chemotherapy resistance by regulating TWF1 and IL-11. Nat Commun. 2013;4(1):1393.

33. Zhang Y, Wang Y, Wei Y, et al. MiR-129-3p promotes docetaxel resistance of breast cancer cells via CP110 inhibition. Sci Rep. 2015; 5:15424.

34. Zhou M, Liu ZY, Ding Y, et al. MicroRNA-125b confers the resistance of breast cancer cells to paclitaxel through suppression of pro-apoptotic Bcl-2 antagonist killer 1 (Bak1) expression. J Biol Chem. 2010; 285(28):21496-21507.

35. Yang Q, Wang Y, Lu X, et al. MiR-125b regulates epithelialmesenchymal transition via targeting Sema4C in paclitaxel-resistant breast cancer cells. Oncotarget. 2015;6(5):3268-3279.

36. Liang $\mathrm{Z}, \mathrm{Wu} \mathrm{H}$. Involvement of miR-326 in chemotherapy resistance of breast cancer through modulating expression of multidrug resistanceassociated protein 1. Biochem Pharmacol. 2010;79(6):817-824.

37. Ye FG, Song C, Cao ZG, et al. Cytidine deaminase axis modulated by miR-484 differentially regulates cell proliferation and chemoresistance in breast cancer. Cancer Res. 2015;75(7):1504-1515.

38. $\mathrm{Hu} \mathrm{Y,} \mathrm{Xu} \mathrm{K.} \mathrm{miR-218} \mathrm{targets} \mathrm{survivin} \mathrm{and} \mathrm{regulates} \mathrm{resistance} \mathrm{to}$ chemotherapeutics in breast cancer. Breast Cancer Res Treat. 2015; 151(2):269-280.

39. $\mathrm{Hu}$ Y, Qiu Y, Yagüe E, et al. miRNA-205 targets VEGFA and FGF2 and regulates resistance to chemotherapeutics in breast cancer. Cell Death Dis. 2016;7(6):e2291.

40. Vargo-Gogola T, Rosen JM. Modelling breast cancer: one size does not fit all. Nat Rev Cancer. 2007;7(9):659-672.

41. Nicholson RI, Johnston SR. Endocrine therapy - current benefits and limitations. Breast Cancer Res Treat. 2005;93 (Suppl 1):S3-S10. 
42. Miller TE, Ghoshal K, Ramaswamy B, et al. MicroRNA-221/222 confers tamoxifen resistance in breast cancer by targeting $\mathrm{p} 27 \mathrm{Kip} 1$. J Biol Chem. 2008;283(44):29897.

43. Cui J, Yang Y, Li H, et al. MiR-873 regulates ER $\alpha$ transcriptional activity and tamoxifen resistance via targeting CDK3 in breast cancer cells. Oncogene. 2015;34(30):3895.

44. Ring A, Dowsett M. Mechanisms of tamoxifen resistance. Endocr Relat Cancer. 2004;11(4):643.

45. Cittelly DM, Das PM, Salvo VA, et al. Oncogenic HER2\{Delta $\} 16$ suppresses miR-15a/16 and deregulates BCL-2 to promote endocrine resistance of breast tumors. Carcinogenesis. 2010;31(12):2049-2057.

46. Lü M, Ding K, Zhang G, et al. MicroRNA-320a sensitizes tamoxifenresistant breast cancer cells to tamoxifen by targeting ARPP-19 and ERR $\gamma^{*}$. Sci Rep. 2015;5:8735.

47. Liu ZR, Song Y, Wan LH, et al. Over-expression of miR-451a can enhance the sensitivity of breast cancer cells to tamoxifen by regulating 14-3-3 $\zeta$, estrogen receptor $\alpha$, and autophagy. Life Sci. 2016;149:104-113.

48. Yu X, Luo A, Liu Y, et al. MiR-214 increases the sensitivity of breast cancer cells to tamoxifen and fulvestrant through inhibition of autophagy. Mol Cancer. 2015;14:208.

49. Cittelly DM, Das PM, Spoelstra NS, et al. Downregulation of miR342 is associated with tamoxifen resistant breast tumors. Mol Cancer. 2010;9(1):317.

50. Ward A, Balwierz A, Zhang JD, et al. Re-expression of microRNA375 reverses both tamoxifen resistance and accompanying EMT-like properties in breast cancer. Oncogene. 2012;32(9):1173.

51. Ikeda K, Horieinoue K, Ueno T, et al. miR-378a-3p modulates tamoxifen sensitivity in breast cancer MCF-7 cells through targeting GOLT1A. Sci Rep. 2015;5:13170.

52. Ujihira T, Ikeda K, Suzuki T, et al. MicroRNA-574-3p, identified by microRNA library-based functional screening, modulates tamoxifen response in breast cancer. Sci Rep. 2015;5:7641.

53. Sachdeva M, Wu H, Ru P, et al. MicroRNA-101-mediated Akt activation and estrogen-independent growth. Oncogene. 2011;30:(7):822.

54. Zugmaier G, Ennis BW, Deschauer B, et al. Transforming growth factors type beta 1 and beta 2 are equipotent growth inhibitors of human breast cancer cell lines. J Cell Physiol. 1989;141(2):353-361.

55. McEarchern JA, Kobie JJ, Mack V, et al. Invasion and metastasis of a mammary tumor involves TGF-beta signaling. Int J Cancer. 2001; 91(1):76-82.

56. Shi W, Gerster K, Alajez NM, et al. MicroRNA-301 mediates proliferation and invasion in human breast cancer. Cancer Res. 2011;71(8): 2926-2637.

57. Hynes NE, MacDonald G. ErbB receptors and signaling pathways in cancer. Curr Opin Cell Biol. 2009;21(2):177-184.

58. Baselga J, Swain SM. Novel anticancer targets: revisiting ERBB2 and discovering ERBB3. Nat Rev Cancer. 2009;9:463-475.

59. Cobleigh MA, Vogel CL, Tripathy D, et al. Multinational study of the efficacy and safety of humanized anti-HER2 monoclonal antibody in women who have HER2-overexpressing metastatic breast cancer that has progressed after chemotherapy for metastatic disease. J Clin Oncol. 1999; 17:2639-2648.

60. Rusnak DW, Lackey K, Affleck K, et al. The effects of the novel, reversible epidermal growth factor receptor/ErbB-2 tyrosine kinase inhibitor, GW2016, on the growth of human normal and tumor-derived cell lines in vitro and in vivo. Mol Cancer Ther. 2001;1:85-94.

61. Ichikawa T, Sato F, Terasawa K, et al. Trastuzumab produces therapeutic actions by upregulating miR-26a and miR-30b in breast cancer cells. PLoS One. 2012;7(2):e31422.

62. Ock CY, Lee KW, Jin WK, et al. Optimal patient selection for trastuzumab treatment in HER2-positive advanced gastric cancer. Clin Cancer Res. 2015;21(11):2520.

63. Yeo B, Kotsori K, Mohammed K, et al. Long-term outcome of HER2 positive metastatic breast cancer patients treated with first-line trastuzumab. Breast. 2015;24(6):751-757.

64. lamon DJ, Leyland-Jones B, Shak S, et al. Use of chemotherapy plus a monoclonal antibody against HER2 for metastatic breast cancer that overexpresses HER2. N Engl J Med. 2001;344(11):783-792.
65. Marty M, Cognetti F, Maraninchi D, et al. Randomized phase II trial of the efficacy and safety of trastuzumab combined with docetaxel in patients with human epidermal growth factor receptor 2-positive metastatic breast cancer administered as first-line treatment: the M77001 study group. J Clin Oncol. 2005;23(19):4265-4274.

66. Esteva FJ, Valero V, Booser D, et al. Phase II study of weekly docetaxel and trastuzumab for patients with HER-2-overexpressing metastatic breast cancer. J Clin Oncol. 2002;20(7):1800-1808.

67. Wang L, Zhang Q, Zhang J, et al. PI3K pathway activation results in low efficacy of both trastuzumab and lapatinib. BMC Cancer. 2011; $11: 248$.

68. Liu L, Greger J, Shi H, et al. Novel mechanism of lapatinib resistance in HER2-positive breast tumor cells: activation of AXL. Cancer Res. 2009;69:6871-6878.

69. Browne BC, O’Brien N, Duffy MJ, et al. HER-2 signaling and inhibition in breast cancer. Curr Cancer Drug Targets. 2009;9:419-438.

70. Nahta R, Esteva FJ. Trastuzumab: triumphs and tribulations. Oncogene. 2007;26:3637-3643.

71. Gong C, Yao Y, Wang Y, et al. Up-regulation of miR-21 mediates resistance to trastuzumab therapy for breast cancer. J Biol Chem. 2011;286(21):19127-19137.

72. Nagata $Y$, Lan KH, Zhou X, et al. PTEN activation contributes to tumor inhibition by trastuzumab, and loss of PTEN predicts trastuzumab resistance in patients. Cancer Cell. 2004;6(2):117-127.

73. De ML, Bottai G, Nuciforo PG, et al. MicroRNA-21 links epithelial-tomesenchymal transition and inflammatory signals to confer resistance to neoadjuvant trastuzumab and chemotherapy in HER2-positive breast cancer patients. Oncotarget. 2015;6(35):37269-37280.

74. Nielsen BS, Balslev E, Poulsen TS, et al. miR-21 expression in cancer cells may not predict resistance to adjuvant trastuzumab in primary breast cancer. Front Oncol. 2014;4:207.

75. Ye X, Bai W, Zhu H, et al. MiR-221 promotes trastuzumab-resistance and metastasis in HER2-positive breast cancers by targeting PTEN. BMB Rep. 2014;47(5):268-273

76. Jung EJ, Santarpia L, Kim J, et al. Plasma microRNA 210 levels correlate with sensitivity to trastuzumab and tumor presence in breast cancer patients. Cancer. 2012;118(10):2603-2614.

77. Wu H, Zhu S, Mo Y-Y. Suppression of cell growth and invasion by miR-205 in breast cancer. Cell Res. 2009;19(4):439-448.

78. De CA, Volpe S, Budani MC, et al. miR-205-5p-mediated downregulation of ErbB/HER receptors in breast cancer stem cells results in targeted therapy resistance. Cell Death Dis. 2015;6:e1823.

79. Bai WD, Ye XM, Zhang MY, et al. MiR-200c suppresses TGF- $\beta$ signaling and counteracts trastuzumab resistance and metastasis by targeting ZNF217 and ZEB1 in breast cancer. Int J Cancer. 2014;135(6): 1356-1368.

80. Ma T, Yang L, Zhang J. miRNA-542-3p downregulation promotes trastuzumab resistance in breast cancer cells via AKT activation. Oncol Rep. 2015;33(3):1215-1220.

81. Ye XM, Zhu HY, Bai WD, et al. Epigenetic silencing of miR-375 induces trastuzumab resistance in HER2-positive breast cancer by targeting IGF1R. BMC Cancer. 2014;14:134.

82. Corcoran C, Rani S, Breslin S, et al. miR-630 targets IGF1R to regulate response to HER-targeting drugs and overall cancer cell progression in HER2 over-expressing breast cancer. Mol Cancer. 2014;13:71.

83. Venturutti L, Russo RIC, Rivas MA, et al. MiR-16 mediates trastuzumab and lapatinib response in ErbB-2-positive breast and gastric cancer via its novel targets CCNJ and FUBP1. Oncogene. 2016;35(48): 6189-6202.

84. Huynh FC, Jones FE. MicroRNA-7 inhibits multiple oncogenic pathways to suppress HER $2 \Delta 16$ mediated breast tumorigenesis and reverse trastuzumab resistance. PLoS One. 2014;9(12):e114419.

85. Zhao M, Ramaswamy B. Mechanisms and therapeutic advances in the management of endocrine-resistant breast cancer. World J Clin Oncol. 2014;5(3):248-262.

86. Clarke R, Skaar TC, Bouker KB, et al. Molecular and pharmacological aspects of antiestrogen resistance. J Steroid Biochem Mol Biol. 2001; 76(1-5):71-84. 
87. Bergamaschi A, Katzenellenbogen BS. Tamoxifen down-regulation of miR-451 increases 14-3-3 $\zeta$ and promotes breast cancer cell survival and endocrine resistance. Oncogene. 2012;31(1):39-47.

88. Rao X, Leva GD, Li M, et al. MicroRNA-221/222 confers breast cancer fulvestrant resistance by regulating multiple signaling pathways. Oncogene. 2010;30(9):1082-1097.

89. Roscigno G, Puoti I, Giordano I, et al. MiR-24 induces chemotherapy resistance and hypoxic advantage in breast cancer. Oncotarget. 2017; 8(12):19507-19521.

90. Knezevic J, Pfefferle AD, Petrovic I, et al. Expression of miR-200c in claudin-low breast cancer alters stem cell functionality, enhances chemosensitivity and reduces metastatic potential. Oncogene. 2015; 34(49):5997-6006.

91. Yang Z, Klionsky DJ. Eaten alive: a history of macroautophagy. Nat Cell Biol. 2010;12(9):814.

92. Yang ZJ, Chee CE, Huang S, et al. The role of autophagy in cancer: therapeutic implications. Mol Cancer Ther. 2011;10(9):1533-1541.

93. Carew JS, Nawrocki ST, Kahue CN, et al. Targeting autophagy augments the anticancer activity of the histone deacetylase inhibitor SAHA to overcome Bcr-Abl-mediated drug resistance. Blood. 2007; 110(1):313-322.

94. Hengartner MO. The biochemistry of apoptosis. Nature. 2000; 407(6805):770

95. Reed JC. Bcl-2 family proteins. Oncogene. 1998;17(25):3225-3236.

96. Niu J, Xue A, Chi Y, et al. Induction of miRNA-181a by genotoxic treatments promotes chemotherapeutic resistance and metastasis in breast cancer. Oncogene. 2016;35(10):1302-1313.

97. Kastl L, Brown I, Schofield AC. miRNA-34a is associated with docetaxel resistance in human breast cancer cells. Breast Cancer Res Treat. 2012;31(2):445-454.

98. Vogelstein B, Lane D, Levine AJ. Surfing the p53 network. Nature. 2000;408(6810):307-310.

99. Nurse P. Cyclin dependent kinases and cell cycle control (nobel lecture). Chembiochem. 2002;3(7):596-603.

100. Kitagawa M, Kitagawa K, Kotake Y, Niida H, Ohhata T. Cell cycle regulation by long non-coding RNAs. Cell Mol Life Sci. 2013;70(24): 4785-4794.

101. Chu J, Zhu Y, Liu Y, et al. E2F7 overexpression leads to tamoxifen resistance in breast cancer cells by competing with E2F1 at miR-15a/16 promoter. Oncotarget. 2015;6(31):31944-31957.

102. Danilov AV, Neupane D, Nagaraja AS, et al. DeltaNp63alphamediated induction of epidermal growth factor receptor promotes pancreatic cancer cell growth and chemoresistance. PLoS One. 2011; 6(10):e26815.

103. Boulbes DR, Chauhan GB, Jin Q, et al. CD44 expression contributes to trastuzumab resistance in HER2-positive breast cancer cells. Breast Cancer Res Treat. 2015;151(3):501-513.

104. Shang Y, Cai X, Fan D. Roles of epithelial-mesenchymal transition in cancer drug resistance. Curr Cancer Drug Targets. 2013;13(9): 915-929.

105. Raza U, Saatci Ö, Uhlmann S, et al. The miR-644a/CTBP1/p53 axis suppresses drug resistance by simultaneous inhibition of cell survival and epithelial-mesenchymal transition in breast cancer. Oncotarget. 2016;7(31):49859-49877.

106. Mani SA, Guo W, Liao MJ, et al. The epithelial-mesenchymal transition generates cells with properties of stem cells. Cell. 2008; 133(4):704-715.

107. Boyle P. Triple-negative breast cancer: epidemiological coniderations and recommendations. Ann Oncol. 2012;23 (Suppl 6):vi7-vi12.

108. Foulkes WD, Smith IE, Reis-Filho JS. Triple-negative breast cancer. N Engl J Med. 2010;363(20):1938-1948.

109. Brabletz S, Brabletz T. The ZEB/miR-200 feedback loop - a motor of cellular plasticity in development and cancer? EMBO Rep. 2010; 11(9):670-677.

110. Gregory PA, Bracken CP, Smith E, et al. An autocrine TGF-beta/ ZEB/miR-200 signaling network regulates establishment and maintenance of epithelial-mesenchymal transition. Mol Biol Cell. 2011; 22(10):1686-1698
111. Shimono Y, Zabala M, Cho RW, et al. Downregulation of miRNA200c links breast cancer stem cells with normal stem cells. Cell. 2009; 138(3):592-603.

112. Lim Y-Y, Wright JA, Attema JL, et al. Epigenetic modulation of the miR-200 family is associated with transition to a breast cancer stemcell-like state. J Cell Sci. 2013;126(Pt 10):2256-2266.

113. Shi H, Zhang W, Zhi Q, et al. Lapatinib resistance in HER2+ cancers: latest findings and new concepts on molecular mechanisms. Tumour Biol. Epub 2016 Oct 10.

114. Lin A, Karin M. NF-kappaB in cancer: a marked target. Semin Cancer Biol. 2003;13(2):107-114.

115. Karin M, Cao Y, Greten FR, Li ZW. NF-kappaB in cancer: from innocent bystander to major culprit. Nat Rev Cancer. 2002;2(4): 301-310.

116. Baldwin AS. Control of oncogenesis and cancer therapy resistance by the transcription factor NF-kappaB. J Clin Invest. 2001; 107(3):241-246.

117. Longley DB, Johnston PG. Molecular mechanisms of drug resistance. J Pathol. 2005;205(2):275-292.

118. Hoesel B, Schmid JA. The complexity of NF- $\kappa \mathrm{B}$ signaling in inflammation and cancer. Mol Cancer. 2013;12(1):86.

119. Körner C, Keklikoglou I, Bender C, et al. MicroRNA-31 sensitizes human breast cells to apoptosis by direct targeting of protein kinase C epsilon (PKCepsilon). J Biol Chem. 2013;288(12):8750-8761.

120. Jorissen RN, Walker F, Pouliot N, Garrett TP, Ward CW, Burgess AW. Epidermal growth factor receptor: mechanisms of activation and signalling. Exp Cell Res. 2003;284(1):31-53.

121. Olayioye MA, Neve RM, Lane HA, Hynes NE. The ErbB signaling network: receptor heterodimerization in development and cancer. EMBO J. 2000;19(13):3159-3167.

122. Pegram MD, Finn RS, Arzoo K, Beryt M, Pietras RJ, Slamon DJ. The effect of HER-2/neu overexpression on chemotherapeutic drug sensitivity in human breast and ovarian cancer cells. Oncogene. 1997;15(5):537-547.

123. Chen X, Yeung TK, Wang Z. Enhanced drug resistance in cells coexpressing ErbB2 with EGF receptor or ErbB3. Biochem Biophys Res Commun. 2000;277(3):757-763.

124. Nagane M, Levitzki A, Gazit A, Cavenee WK, Huang HJ. Drug resistance of human glioblastoma cells conferred by a tumorspecific mutant epidermal growth factor receptor through modulation of Bcl-XL and caspase-3-like proteases. Proc Natl Acad Sci US A. 1998; 95(10):5724-5729.

125. Blume-Jensen P, Hunter T. Oncogenic kinase signalling. Nature. 2001;411(6835):355-365.

126. Takahashi-Yanaga F, Kahn M. Targeting Wnt signaling: can we safely eradicate cancer stem cells? Clin Cancer Res. 2010;16(12): 3153-3162.

127. Lv MM, Zhu XY, Chen WX, et al. Exosomes mediate drug resistance transfer in MCF-7 breast cancer cells and a probable mechanism is delivery of P-glycoprotein. Tumour Biol. 2014;35(11):10773-10779.

128. Chen Z, Shi T, Zhang L, et al. Mammalian drug efflux transporters of the ATP binding cassette (ABC) family in multidrug resistance: a review of the past decade. Cancer Lett. 2016;370(1):153-164.

129. Cuconati A, Mukherjee C, Perez D, White E. DNA damage response and MCL-1 destruction initiate apoptosis in adenovirus-infected cells. Genes Dev. 2003;17(23):2922-2932.

130. Yu DD, Wu Y, Shen HY, et al. Exosomes in development, metastasis and drug resistance of breast cancer. Cancer Sci. 2015;106(8): 959-964.

131. Zhong S, Xiu C, Wang D, et al. MicroRNA expression profiles of drug-resistance breast cancer cells and their exosomes. Oncotarget. 2016;7(15):19601-19609.

132. Mao L, Li J, Chen WX, et al. Exosomes decrease sensitivity of breast cancer cells to adriamycin by delivering microRNAs. Tumour Biol. 2016;37(4):5247-5256.

133. Chen WX, Liu XM, Lv MM, et al. Exosomes from drug-resistant breast cancer cells transmit chemoresistance by a horizontal transfer of microRNAs. PLoS One. 2014;9(4):e95240. 
134. Chen WX, Cai YQ, Lv MM, et al. Exosomes from docetaxel-resistant breast cancer cells alter chemosensitivity by delivering microRNAs. Tumour Biol. 2014;35(10):9649.

135. Chen WX, Zhong SL, Ji MH, et al. MicroRNAs delivered by extracellular vesicles: an emerging resistance mechanism for breast cancer. Tumour Biol. 2014;35(4):2883-2892.

136. Wei Y, Lai X, Yu S, et al. Exosomal miR-221/222 enhances tamoxifen resistance in recipient ER-positive breast cancer cells. Breast Cancer Res Treat. 2014;147(2):423-431.

137. O'Brien K, Lowry MC, Corcoran C, et al. miR-134 in extracellular vesicles reduces triple-negative breast cancer aggression and increases drug sensitivity. Oncotarget. 2015;6(32):32774.

138. Challagundla KB, Wise PM, Neviani P, et al. Exosome-mediated transfer of microRNAs within the tumor microenvironment and neuroblastoma resistance to chemotherapy. J Natl Cancer Inst. 2015; 107(7):pii:djv135.

139. Mikamori M, Yamada D, Eguchi H, et al. MicroRNA-155 controls exosome synthesis and promotes gemcitabine resistance in pancreatic ductal adenocarcinoma. Sci Rep. 2017;7:42339.

140. Xia X, Yu S, Li S, et al. Exosomes: decreased sensitivity of lung cancer A549 cells to cisplatin. PLoS One. 2014;9(2):e89534.

141. Feng W, Ma C, Tong Z, et al. Exosomes derived from gemcitabineresistant cells transfer malignant phenotypic traits via delivery of miRNA-222-3p. Mol Cancer. 2017;16(1):132.

142. Qin X, Yu S, Zhou L, et al. Cisplatin-resistant lung cancer cellderived exosomes increase cisplatin resistance of recipient cells in exosomal miR-100-5p-dependent manner. Int J Nanomedicine. 2017; $12: 3721-3733$

143. Corcoran C, Rani S, O'Driscoll L. miR-34a is an intracellular and exosomal predictive biomarker for response to docetaxel with clinical relevance to prostate cancer progression. Prostate. 2014;74(13): 1320-1334.

144. Zheng P, Lei C, Yuan X, et al. Exosomal transfer of tumor-associated macrophage-derived miR-21 confers cisplatin resistance in gastric cancer cells. J Exp Clin Cancer Res. 2017;36(1):53.
145. Lou G, Song X, Yang F, et al. Exosomes derived from miR-122modified adipose tissue-derived MSCs increase chemosensitivity of hepatocellular carcinoma. J Hematol Oncol. 2015;8:122.

146. Munoz JL, Bliss SA, Greco SJ, et al. Delivery of functional antimiR-9 by mesenchymal stem cell-derived exosomes to glioblastoma multiforme cells conferred chemosensitivity. Mol Ther Nucleic Acids. 2013;2:e126.

147. Yuwen DL, Sheng BB, Liu J, et al. MiR-146a-5p level in serum exosomes predicts therapeutic effect of cisplatin in non-small cell lung cancer. Eur Rev Med Pharmacol Sci. 2017;21(11):2650-2658.

148. Ma X, Chen Z, Hua D, et al. Essential role for TrpC5-containing extracellular vesicles in breast cancer with chemotherapeutic resistance. Proc Natl Acad Sci U S A. 2014;111(17):6389.

149. Boelens MC, Wu TJ, Nabet BY, et al. Exosome transfer from stromal to breast cancer cells regulates therapy resistance pathways. Cell. 2014;159(3):499-513.

150. Wang J, Hendrix A, Hernot S, et al. Bone marrow stromal cell-derived exosomes as communicators in drug resistance in multiple myeloma cells. Blood. 2014;124(4):555-566.

151. Neviani P, Fabbri M. Exosomic microRNAs in the tumor microenvironment. Front Med (Lausanne). 2015;2:47.

152. Shedden K, Xie XT, Chandaroy P, Chang YT, Rosania GR. Expulsion of small molecules in vesicles shed by cancer cells: association with gene expression and chemosensitivity profiles. Cancer Res. 2003; 63(15):4331-4337.

153. Safaei R, Larson BJ, Cheng TC, et al. Abnormal lysosomal trafficking and enhanced exosomal export of cisplatin in drugresistant human ovarian carcinoma cells. Mol Cancer Ther. 2005; 4(10):1595-1604.

154. Federici C, Petrucci F, Caimi S, et al. Exosome release and low pH belong to a framework of resistance of human melanoma cells to cisplatin. PLoS One. 2014;9(2):e88193.
OncoTargets and Therapy

\section{Publish your work in this journal}

OncoTargets and Therapy is an international, peer-reviewed, open access journal focusing on the pathological basis of all cancers, potential targets for therapy and treatment protocols employed to improve the management of cancer patients. The journal also focuses on the impact of management programs and new therapeutic agents and protocols on

\section{Dovepress}

patient perspectives such as quality of life, adherence and satisfaction. The manuscript management system is completely online and includes a very quick and fair peer-review system, which is all easy to use. Visit http://www.dovepress.com/testimonials.php to read real quotes from published authors. 